\title{
Arterioventricular relations and their classification Two specimens of arterioventricular discordance and review of published reports
}

\author{
María V. de la Cruz, Mireya Amoedo, Fermin Rivera, and Fause Attie \\ From the Department of Embryology, Instituto Nacional de Cardiología, México 7, D.F.
}

We present a theory which makes it possible to interpret the relation between the different types of truncoconal morphologies and the position of the ventricles, to establish the atrioventricular relations, and to integrate them in the context of the corresponding visceral situs. This theory is based on findings from experimental embryology, i.e. that the cardiac tube is constituted by three segments with specific features which appear at different developmental stages and which give rise to three different heart regions (the atria, the ventricles, and the great arteries with their valvular planes) and on the evidence that the heart is formed by two cardiac primordia with different developmental potentialities.

By means of this theory we systematize the relation of the great arteries and their valvular planes with the position of the ventricles and the atria with the ventricles. We divide the relations of the great arteries with the position of the ventricles into two groups: with arterioventricular concordance and with arterioventricular discordance. Arterioventricular concordance is so called because the relation between the great arteries, and their valvular planes, in the three truncoconal morphologies, allows the spatial position of the ventricles to be identified. In the morphology with crossed great arteries, a pulmonary artery directed from right to left indicates that the anatomically right ventricle is on the right, and one directed from left to right indicates that the anatomically right ventricle is on the left side. In the morphology with transposition of the great arteries, and in partial distorsion of the great arteries, an aorta placed on the right side of the pulmonary artery indicates that the anatomically right ventricle is placed on the right side and one placed on the left side of the pulmonary artery indicates that the anatomically right ventricle is placed on the left side. Arterioventricular discordance is so called because the relation of the great arteries between themselves, and their valvular planes, in the three truncoconal morphologies does not agree with the position of the ventricles, and therefore they do not permit the identification of the spatial position of these cavities.

Each of the above groups comprises two subgroups: with atrioventricular concordance (anatomically right atrium connected with the anatomically right ventricle) and with atrioventricular discordance (anatomically right atrium connected with the anatomically left ventricle). Consequently there are four anatomo-embryological entities.

I) Arterioventricular concordance with atrioventricular concordance This entity includes the normal heart and all the congenital cardiopathies in which there is a normal atrioventricular relation and in which the relations of the great arteries with their valvular planes are concordant with the position of the ventricles.

2) Arterioventricular concordance with atrioventricular discordance The most representative cardiopathy in this group is the so-called corrected transposition of the great arteries, which arises from a developmental disturbance which affects simultaneously the truncus and the bulboventricular loop, causing inversion of both.

3) Arterioventricular discordance with atrioventricular concordance This arises from an isolated inversion of the truncus.

4) Arterioventricular discordance with atrioventricular discordance This is caused by an isolated inversion of the bulboventricular loop.

The last two entities constitute an extremely rare group of cardiopathies of which two examples from our own series are presented. The reports describing this rare group are reviewed. 
The majority of reported cases of transposition of the great arteries, partial distorsion of the great arteries, and crossed arteries indicates that there is a concordance between the relation of the great arteries and their valvular planes with the spatial position of the ventricles. This has made possible the establishment of some rules (De la Cruz and NadalGinard, 1972) for the identification of the spatial position of the ventricles from the orientation of the great arteries. Van Praagh et al. (1964) have also related the position of the great arteries with the type of bulboventricular loop. On the other hand, there is a small group of congenital cardiopathies in which it is not possible to identify the position of the ventricles, nor, therefore, the type of the loop by means of the relation of the great arteries with each other (Van Praagh, 1972).

Recent embryological research (Castro-Quezada, Nadal-Ginard, and De la Cruz, 1972) has shown that the heart tube has three different segments each of which gives origin to an anatomical region with specific anatomical features. These segments are I) the bulboventricular loop, which gives rise to the conus and the ventricles, 2) the truncus, which forms the ascending portion of the aortic arch and the trunk of the pulmonary artery with their respective valvular planes, and 3) the atrial part, which forms the right and left atria. Each of these segments is constituted of two primordia with different developmental potentialities. These embryological facts, and the anatomical findings obtained from the study of the relations between the atria and the ventricles and between the great arteries and the position of the ventricles in the normal heart and congenital cardiopathies, have enabled us to propose a theory which is presented here. This theory makes it possible to understand not only the large group in which the great arteries and their valvular planes agree with the position of the ventricles (arterioventricular concordance), but also the smaller discordant group in which the relation of the great arteries with each other and their valvular planes with each other do not permit the spatial identification of the ventricles. This theory has enabled us also to integrate both these groups with the possible atrioventricular relations.

We present, also, a systematization of the above relations and of the nomenclature, with a review of the cases previously published (Martínez-Picó and Muñoz, 1967; Pérez-Treviño, Hurtado del Río, and Holden, 1972; Van Praagh and Van Praagh, 1966, 1967; Anderson, Arnold, and Jones, 1972; Lev and Rowlatt, 1961), in which the relations of the great arteries and their vulvular planes does not correspond with the position of the ventricles. Two of our own specimens belonging to this group are presented.

\section{Embryological considerations}

Experimental embryology has proved that there are three different segments in the embryonic heart which appear at different stages of development (Castro-Quezada et al., 1972), i.e. the bulboventricular loop, the atria, and the truncus. Each of these segments gives origin, respectively, to the ventricles, the atria, and the great arteries with their valvular planes (ascending portion of the aorta and pulmonary artery trunk). It is known that the bulboventricular loop and the truncus are formed by the two cardiac primordia, right and left, while in the formation of both atria there is only one cardiac primordium involved. (Rosenquist and DeHaan, 1966; Stalsberg and DeHaan, 1969). Experimental embryology has shown that the morphological expression of each of these primordia, when separated from each other, is different (NadalGinard and García, 1972). It has also been established that the aortic and pulmonary sigmoid valve cusps originate in the walls of the truncus (Van Mierop, 1969) and that the conus forms part of the bulboventricular loop (Castro-Quezada et al., 1972; Rosenquist and DeHaan, 1966; Stalsberg and DeHaan, 1969; Van Mierop, 1969). These embryological considerations allow us to interpret a group of congenital cardiopathies.

\section{I) Arterioventricular concordance with atrio- ventricular concordance in situs solitus (Fig. I $A$ and $2 A, B, C$ )}

The normal concordant relation in situs solitus between the atria, the ventricles, and the arterial pedicle is because the right cardiac primordium has developmental potentialities of the right primordium and the left primordium has developmental potentialities of the left for the atria, the bulboventricular loop, and the trunk (De la Cruz et al., 1967) (Fig. IA, $\left.a_{1}\right)$. This results in the anatomically right atrium being on the right (visceroatrial concordance) (Fig. IA, $\left.a_{1}, a_{6}\right)$, the development of a bulboventricular loop convex to the right and concave to the left (anatomically right ventricle on the right side) (Fig. IA, $a_{1}, a_{5}$ ), the anatomically right atrium communicating with the anatomically right ventricle, both on the right side (atrioventricular concordance) ${ }^{1}$ (Fig. IA, $a_{5}, a_{6}$ ), the truncus septum being oriented nor-

1 Atrioventricular concordances are characterized by the anatomically right atrium communicating with the anatomically right ventricle and both being placed on the same side, independently of their position in the chest. In situs solitus they are both on the right; in situs inversus on the left. 


\section{SITUS SOLITUS}

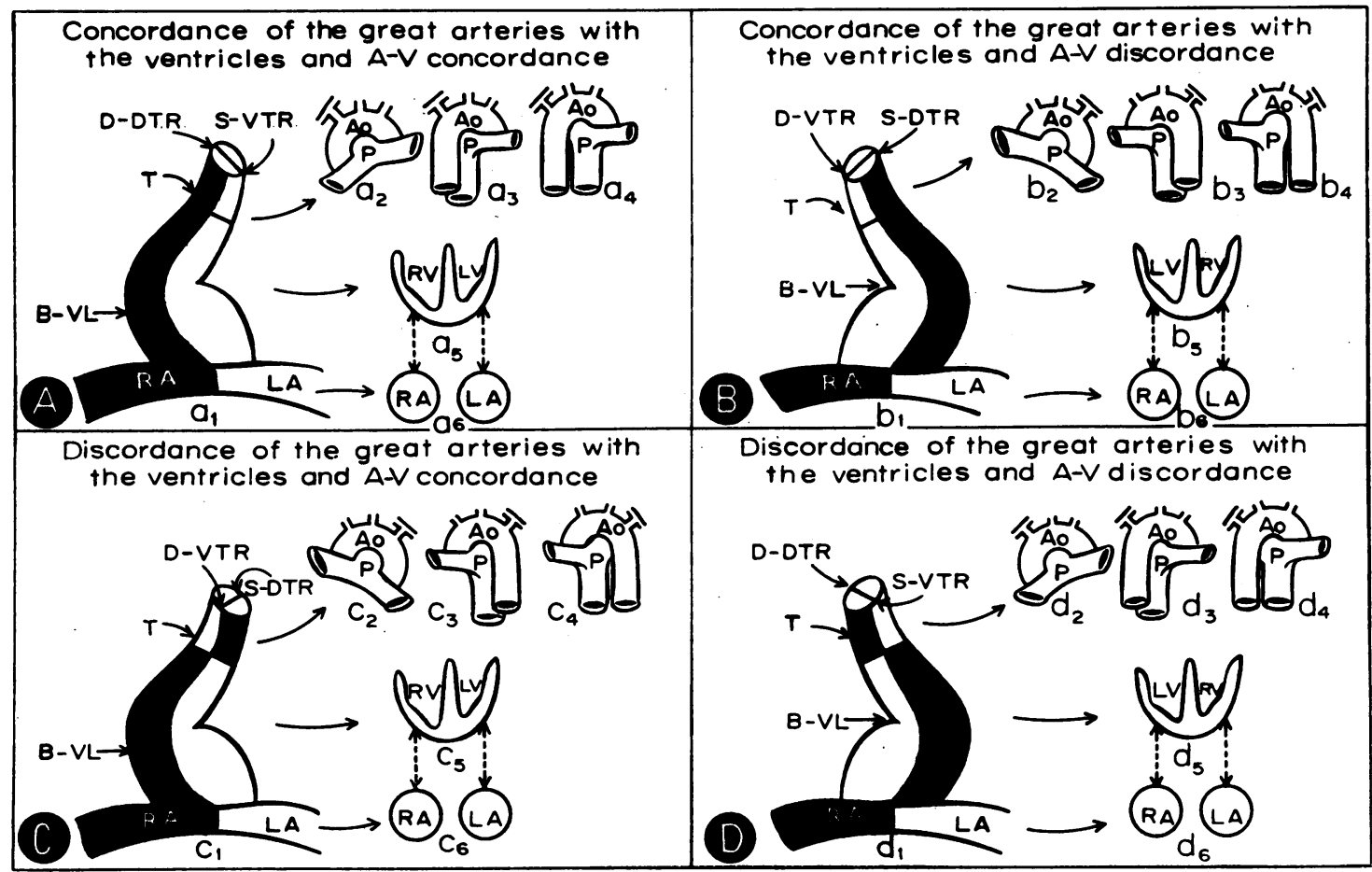

FIG. I Diagrams representing the relation of the different segments of the embryonic heart with the various anatomical structures which originate from each of those segments during the looping stage. The black areas represent the halves of the cardiac tube with developmental potentialities of the right primordium, and the white areas the halves of the tube with left primordial developmental potentialities. $a_{1}$ ) Ventral view of normal development of the cardiac tube. $b_{1}$ ) Diagram representing the inversion of the cardiac primordia at the level of the truncus and the bulboventricular loop simultaneously. $c_{1}$ ) Diagram representing the inversion of the primordia affecting the truncus exclusively. $d_{1}$ ) Diagram representing the inversion of the primordia affecting the bulboventricular loop exclusively. $a_{2}, b_{2}, c_{2}, d_{2}$ ) Crossed arteries. $a_{3}$, $b_{3}, c_{3}, d_{3}$ ) Transposition of the great arteries. $a_{4}, b_{4}, c_{4}, d_{4}$ ) Partial distorsion of the great arteries. $a_{5}, b_{5}, c_{5}, d_{5}$ ) Spatial position of the ventricles. $\left.a_{6}, b_{6}, c_{6} d_{6}\right)$ Spatial position of the atria. The arrows indicate the atrioventricular relation.

Key to abbreviations: $D-D T R=$ Dextrodorsal truncus ridge. $S-V T R=$ Sinistroventral truncus ridge. $D-V T R=$ Dextroventral truncus ridge. $S-D T R=$ Sinistrodorsal truncus ridge. $T=$ Truncus. $B-V L=$ Bulboventricular loop. $R A=$ Right atrium. $L A=$ Left atrium. $R V=$ Right ventricle. $L V=$ Left ventricle. $P=$ Pulmonary artery. $A o=$ Aorta.

mally from right to left (Fig. IA, $a_{1}$ ) in either of its three fundamental morphologies with normal torsion (crossed arteries) (Fig. IA, $a_{2}$ ), or straight (De la Cruz and da Rocha, 1956) (transposition of the great arteries ${ }^{1}$ ) (Fig. IA, $a_{3}$ ), or with a $90^{\circ}$ rotation ${ }^{1}$ We define transpositions of the great arteries as a condition with an aorta arising in front of the horizontal portion of the crista supraventricularis, occupying an anterior position with respect to the pulmonary artery and parallel to it in the sagittal plane.
(De la Cruz and da Rocha, 1956) (partial distorsion of the great arteries ${ }^{1}$ ) (Fig. IA, $\mathrm{a}_{4}$ ), so that the arterial pedicle and its valvular planes are concordant with the position of the ventricles (Fig. IA, $\mathrm{a}_{2}$ to $\mathrm{a}_{5}$ and Fig. 2A, B, C). Thus, the pulmonary artery directed from right to left in the morphology of

${ }^{1}$ In partial distorsion, the pulmonary artery arises in front of the horizontal portion of the crista supraventricularis and both arteries are parallel on the frontal plane. 


\section{SITUS SOLITUS}

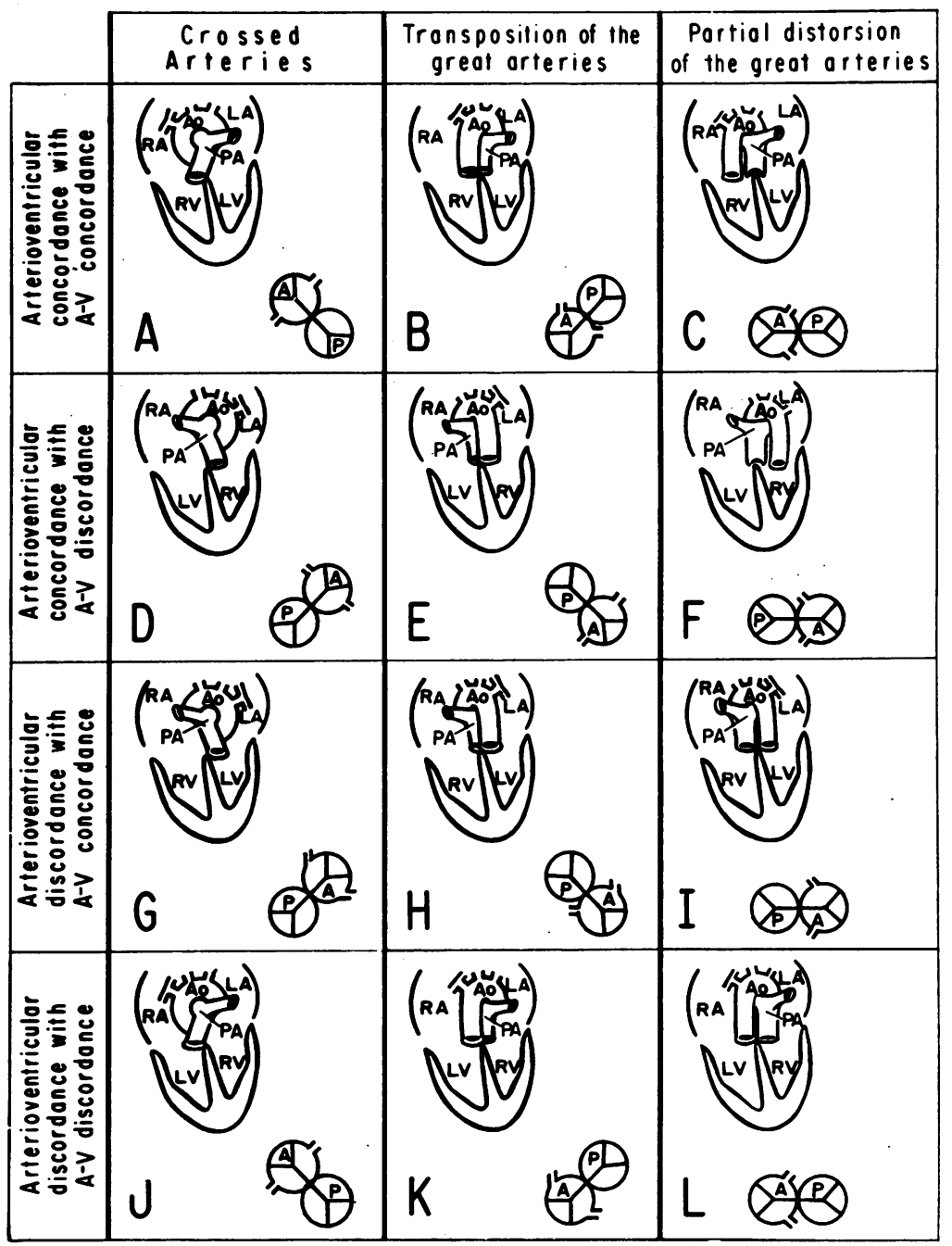

FIG. 2 Diagrams representing the concordant and discordant relations of the great arteries and their valvular planes with the position of the ventricles in the three truncoconal morphologies, integrated with the atrioventricular relations (concordant and discordant) in the context of situs solitus.

Key to abbreviations: $R A=$ Right atrium. $L A=$ Left atrium. Ao=Aorta. $P A=P u l m o n a r y$ artery. $A=$ Aortic sigmoid valve cusps. $P=$ Pulmonary sigmoid valve cusps. $A-V=A$ trioventricular.

crossed arteries and the position of the aorta to the right of the pulmonary artery in transposition of the great arteries and in partial distorsion of the great arteries, indicate that the anatomically right ventricle is situated to the right (De la Cruz and NadalGinard, 1972) (Fig. IA, $a_{2}$ to $a_{5}$ and Fig. 2A, B, C). This group includes the normal heart and all the cardiopathies with atrioventricular concordance and concordance of the great arteries and their valvular planes with the position of the ventricles.

2) Arterioventricular concordance associated with atrioventricular discordance in situs solitus (Fig. $\mathrm{IB}$ and $2 \mathrm{D}, \mathrm{E}, \mathrm{F}$ )

Atrioventricular discordance with concordance of the great arteries and the ventricles may be caused, 
as previously pointed out (De la Cruz et al., 1967), by an inversion of the developmental potentialities of the heart primordia so that the right primordium has potentialities of the left one and vice versa, the condition affecting only the truncus and the bulboventricular loop but not the atria (compare Fig. I $B, b_{1}$ with IA, $a_{1}$ ). This would cause the anatomically right atrium to be on the right side (visceroatrial concordance) (Fig. $\mathrm{IB}, \mathrm{b}_{1}, \mathrm{~b}_{6}$ ), and the bulboventricular loop to be developed convex to the left and concave to the right which is abnormal for situs solitus (anatomically right ventricle placed on the left) (compare Fig. IB, $b_{1}, b_{5}$ with IA, $a_{1}, a_{5}$ ) so that the anatomically right atrium would communicate with the anatomically left ventricle placed on the right (atrioventricular discordance ${ }^{1}$ ) (Fig. IB, $b_{5}, b_{6}$ ) and the dextrodorsal ridge of the truncus would be sinistrodorsal with the sinistroventral becoming dextroventral. Therefore, the truncal ridges would be abnormally oriented in relation to their right and left position and not dorsoventral (compare Fig. IB, $b_{1}$, with IA, $a_{1}$ ). This alteration would give rise to a truncus septum oriented from left to right in any of the three fundamental morphologies with a torsion of $180^{\circ}$ (crossed arteries), straight (transposition of the great arteries), or with a $90^{\circ}$ rotation (partial distorsion of the great arteries) which would cause the arterial pedicle and its valvular planes to be concordant with the position of the ventricles and discordant with the atria (compare Fig. 2D, E, F with 2 $A, B, C)$. Consequently, the pulmonary artery directed from left to right with crossed arteries, and the position of the aorta to the left of the pulmonary artery in transposition of the great arteries and in partial distorsion of the great arteries, indicates that the anatomically right ventricle is placed on the left (De la Cruz and Nadal-Ginard, I972) (Fig. IB, $b_{2}$ to $b_{5}$ and Fig. 2D, E. F). These cardiopathies are characterized by a discordance of the atria with the ventricles and the arterial pedicle and a concordance of the pedicle and its valvular planes with the position of the ventricles. This malformation in transposition of the great arteries has been designated corrected transposition of the great arteries.

3) Arterioventricular discordance associated with atrioventricular concordance in situs solitus (Fig. IC and $2 G, H, I$ )

An abnormal, discordant, relation of the great arteries and their valvular planes with the position of

\footnotetext{
1 Atrioventricular discordances are characterized because the anatomically right atrium communicates with the anatomically left ventricle independently of their position in the chest. In situs solitus both are on the right; in situs inversus, both are on the left.
}

the ventricles together with atrioventricular concordance in situs solitus could be caused by an inversion of the developmental potentialities of the heart primordia, so that the right primordium has developmental potentialities of a left one and vice versa but affecting exclusively the truncus and not the bulboventricular loop or the atria (compare Fig. IC, $c_{1}$ with IA, $a_{1}$ ). This would cause the anatomically right atrium to be placed on the right (visceroatrial concordance) (Fig. $\mathrm{IC}, \mathrm{c}_{1}, \mathrm{c}_{6}$ ), a normal bulboventricular loop to be developed for its situs solitus, i.e. convex to the right and concave to the left (anatomically right ventricle on the right side) (compare Fig. IC, $c_{1}, c_{5}$ with IA, $a_{1}, a_{5}$ ), the anatomically right atrium to communicate with the anatomically right ventricle placed on the right side (atrioventricular concordance) (Fig. IC, $\mathrm{c}_{5}, \mathrm{c}_{6}$ ) but the dextrodorsal ridge of the truncus to be sinistrodorsal and the sinistroventral to be dextroventral because the right half of the truncus had left developmental potentialities and vice versa (compare Fig. IC, $c_{1}$ with IA, $a_{1}$ ). This disturbance would give rise to a truncus septum oriented from left to right in any of the three fundamental morphologies (crossed arteries, transposition of the great arteries, and partial distorsion of the great arteries) which would cause the arterial pedicle and its valvular planes to be discordant with the position of the ventricles and of the atria (compare Fig. 2G, H, I with $2 \mathrm{~A}, \mathrm{~B}, \mathrm{C}$ ). Consequently, the pulmonary artery directed from left to right in the morphology of crossed arteries, and the position of the aorta to the left of the pulmonary artery in transposition of the great arteries and in partial distorsion of the great arteries, would not indicate that the anatomically right ventricle is placed on the left side; on the contrary, they are associated with an anatomically right ventricle placed on the right (compare Fig. $2 G, H$. I with $2 D$, E, F). These cardiopathies are characterized by atrioventricular concordance but discordance of the great arteries and their valvular planes with the position of the ventricles.

4) Arterioventricular discordance associated with atrioventricular discordance in situs solitus (Fig. ID and 2J, K, L.)

An abnormal, discordant, relation of the arterial pedicle with the ventricles in the variety of atrioventricular discordance in situs solitus, could be caused by an inversion of the developmental potentialities of the heart primordia, in such a way that the right primordium would have developmental potentialities of the left one and vice versa but affecting only the bulboventricular loop and not the truncus or the atria (compare Fig. ID, $d_{1}$ with IA, $\left.a_{1}\right)$. This would determine that the anatomically 


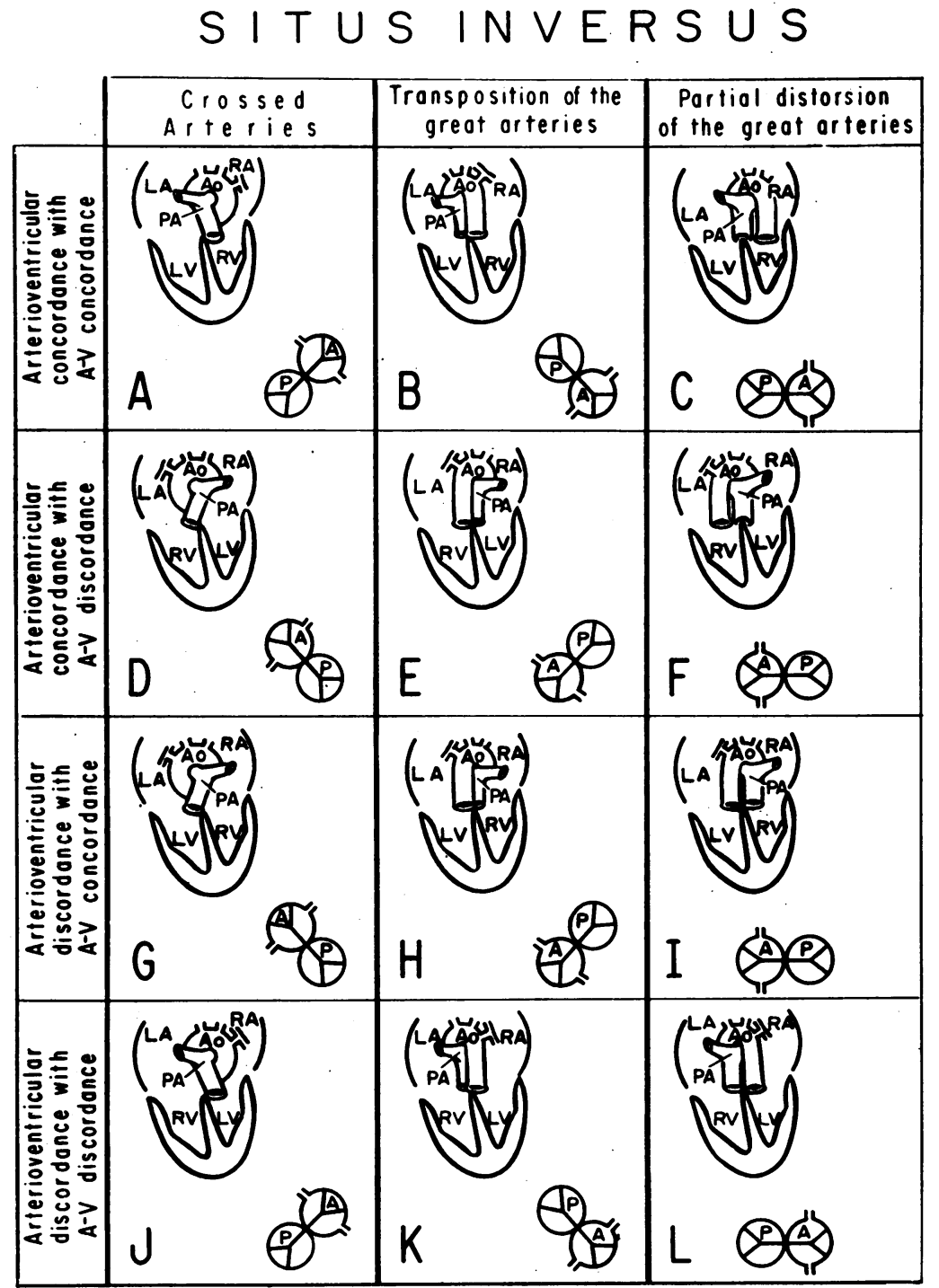

FIG. 3 Diagrams representing the concordant and discordant relations of the great arteries and their valvular planes with the position of the ventricles in the three truncoconal morphologies, integrated with the atrioventricular relations (concordant and discordant) in the context of situs inversus.

Key to abbreviations: $R A=$ Right atrium. $L A=$ Left atrium. Ao=Aorta. $P A=$ Pulmonary artery. $A=$ Aortic sigmoid valve cusps. $P=P$ ulmonary sigmoid valve cusps. $A-V=$ Atrioventricular.

right atrium is placed on the right (visceroatrial concordance) (Fig. $\mathrm{ID}, \mathrm{d}_{1}, \mathrm{~d}_{6}$ ), that the bulboventricular loop develops abnormally for its situs solitus, convex to the left and concave to the right (anatomically right ventricle placed on the left side) (compare Fig. ID, $d_{1}, d_{5}$ with $I A, a_{1}, a_{5}$ ), and that, consequently, the anatomically right iatrium com- municates with the anatomically left ventricle, both located on the right side (atrioventricular discordance) (Fig. $\mathrm{ID}, \mathrm{d}_{5}, \mathrm{~d}_{6}$ ), with the truncus ridges developing normally according to the situs, dextrodorsal, and sinistroventral (compare Fig. ID, $d_{1}$ with IA, $a_{1}$ ). Consequently, the truncus septum would be oriented from right to left in any of its 
three fundamental morphologies (crossed arteries, transposition of the great arteries, and partial distorsion of the great arteries) which in turn will cause the arterial pedicle and its valvular planes to be discordant with the position of the ventricles and concordant with the atria (compare Fig. $2 \mathrm{~J}, \mathrm{~K}, \mathrm{~L}$ with $2 D, E, F)$. Therefore, the pulmonary artery directed from right to left in the morphology with crossed arteries, and the position of the aorta to the right of the pulmonary artery in transposition of the great arteries, and in partial distorsion of the great arteries, would not indicate that the anatomically right ventricle is placed on the right; on the contrary, they are associated with an anatomically right ventricle placed on the left side (compare Fig. 2J, K, L. with $2 \mathrm{~A}, \mathrm{~B}, \mathrm{C}$ ). These cardiopathies are characterized by atrioventricular discordance with discordance of the great arteries and their valvular planes with the position of the ventricles.

It has previously been pointed out that it is quite probable that situs inversus may be caused by the right hemiblastoderm having left-sided features and vice versa (De la Cruz et al., 1967). In that case, the normal right heart primordium of situs inversus will have developmental potentialities of the left primordium. On this basis, we can interpret the different varieties of concordance and discordance in situs inversus between the three segments which characterize the embryonic heart: the atria, the bulboventricular loop (ventricles), and the truncus (arterial pedicle) will give rise to anatomical mirrorimages with respect to those in situs solitus (commare Fig. 2 with Fig. 3).

\section{Anatomical features, classification, and nomenclature}

From the embryological concepts outlined above, an anatomical characterization of discordances and concordances of the great arteries and their valvular planes with the position of the ventricles may be given, thus establishing their relation with the atria, and allowing us to systematize them and develop a proper nomenclature.

I) Anatomical characteristics of concordance and discordance of the great arteries with the ventricles

A) Arterioventricular concordance In concordance of the arterial pedicle with the position of the ventricles, the valvular planes in the three truncoconal morphologies (previously listed) correspond to the position of the ventricles, whether the anatomically right ventricle is placed on the right or on the left side (Fig. $2 A$ to $F$ and $3 A$ to $F$ ). Furthermore, the rules, previously established (De la Cruz and Nadal-Ginard, 1972) which apply for the recognition of the position of the ventricles by means of the relation of the great arteries to each other, are complied with. Thus, in crossed arteries a pulmonary artery directed right to left/indicates that the anatomically right ventricle is placed on the right side (Fig. 2A and $3 \mathrm{D}$ ) and if this artery is directed from left to right, the anatomically right ventricle is on the left side (Fig. $2 \mathrm{D}$ and $3 \mathrm{~A}$ ). In transposition of the great arteries and in partial distorsion of the great arteries, the position of the aorta with respect to the pulmonary artery serves to determine the position of the anatomically right ventricle. Thus, an aorta placed on the right side of the pulmonary artery indicates that the anatomically right ventricle is on the right side (Fig. $2 \mathrm{~B}, \mathrm{C}$ and $3 \mathrm{E}$, F), and an aorta placed on the left side of the pulmonary artery indicates that the anatomically right ventricle is placed on the left side (Fig. $2 \mathrm{E}, \mathrm{F}$ and 3B, C).

B) Arterioventricular discordance In discordances of the arterial pedicle with the position of the ventricles, the valvular planes are related spatially in the three truncoconal morphologies exclusively with the spatial orientation of the great arteries and not with the position of the ventricles, unlike the situation when there is concordance of the great arteries with the position of the ventricles (compare $G$ to $L$ with $A$ to $F$ in Fig. 2 and 3). Therefore, in the case of crossed arteries with an anatomically right ventricle placed on the right, the valvular plane appears as the one observed when in this truncoconal morphology the anatomically right ventricle is on the left side (compare G with D in Fig. 2); in transposition of the great arteries, and in partial distorsion of the great arteries, with an anatomically right ventricle placed on the right, the valvular plane is that which one sees in these same truncoconal morphologies, when the anatomically right ventricle is on the left side (compare $\mathrm{H}$ with $\mathrm{E}$ and $\mathrm{I}$ with $\mathrm{F}$ in Fig. 2). The rules previously proposed (De la Cruz and Nadal-Ginard, 1972) for the determination of the position of the ventricle from the spatial orientation of the great arteries, when there is concordance between the truncus and the bulboventricular loop (between the great arteries and their valvular planes with the position of the ventricles), cannot be applied when there is discordance between the truncus and the loop. Thus, in crossed arteries, the direction of the pulmonary artery does not indicate the position of the anatomically right ventricle and, therefore, a pulmonary artery directed from right to left is associated with the anatomically right ventricle placed on the left (compare Fig. 2J and $3 G$ with $2 \mathrm{~A}$ and $3 \mathrm{D}$ ) and a pulmonary artery directed from left to right is associated with an anatomically 

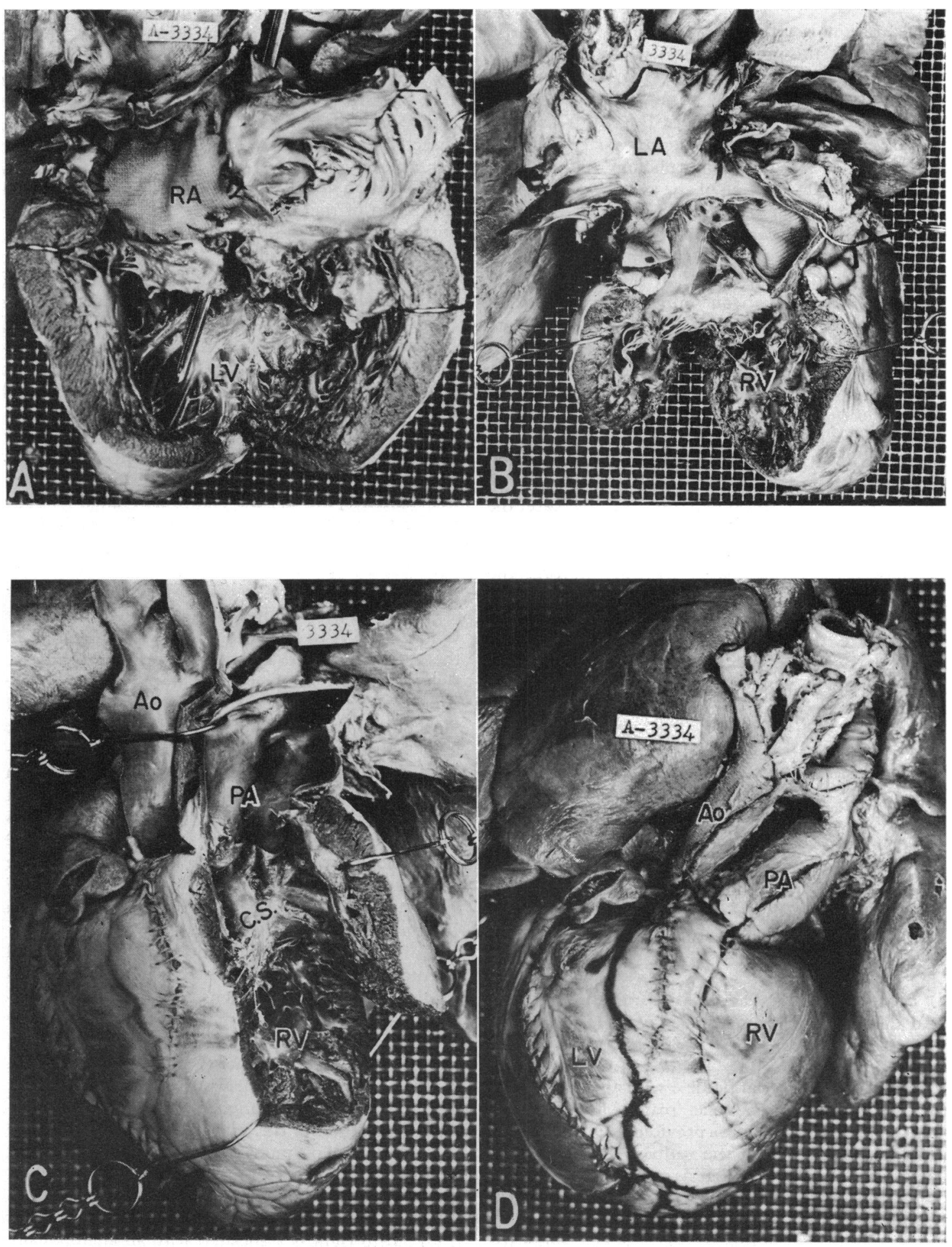
right ventricle placed on the right side (compare Fig. $2 G$ and $3 J$ with $2 D$ and $3 A$ ), which is the opposite of what happens when there is concordance of the great arteries and their valvular planes with the position of the ventricles. In transposition of the great arteries and in partial distorsion of the great arteries, the position of the aorta with respect to the pulmonary artery does not permit the identification of the position of the anatomically right ventricle. Thus, an aorta placed on the right side of the pulmonary artery is associated with an anatomically right ventricle placed on the left side (compare Fig. $2 \mathrm{~K}, \mathrm{~L}$ and $3 \mathrm{H}$, I with $2 \mathrm{~B}, \mathrm{C}$ and $3 \mathrm{E}, \mathrm{F}$ ) and an aorta placed on the left side of the pulmonary artery is associated with an anatomically right ventricle placed on the right side (compare Fig. $2 \mathrm{H}, \mathrm{I}$ and 3 $\mathrm{K}, \mathrm{L}$ with $2 \mathrm{E}, \mathrm{F}$ and $3 \mathrm{~B}, \mathrm{C}$ ), as opposed to what happens when there is concordance of the arterial pedicle with the position of the ventricles. In both arterioventricular concordance and discordance, the important thing is the relation of the great arteries and their valvular planes to the position of the ventricles, regardless of from which ventricle these vessels emerge.

\section{2) Classification}

After establishing the anatomico-embryological criterion for interpretation and identification of discordance of the great arteries and their valvular planes with the ventricles, it is necessary to consider the atrioventricular relations, in order to derive a classification which is useful both for the anatomist and the clinician (Table).

\section{3) Nomenclature}

The group of cardiopathies in which the orientation of the great arteries and their valvular planes does not correspond with the spatial position of the ventricles may be named 'discordant' in addition to the denomination of the truncoconal morphology. Thus, discordant crossed arteries, discordant transposition of the great arteries, discordant partial distorsion of the great arteries would be appropriate designations. As noted above, the arterioventricular discordance may be due, from an embryological standpoint, to a disturbance of the bulboventricular loop or of the truncus. In the first case, the arterioventricular discordance will associate with atrioventricular discordance, for which reason the nomenclature could be, for example, discordant transposition of the great arteries with atrioventricular discordance. In the second case, the cardiopathy will only have arterioventricular discordance and could be designated, for example, discordant crossed arteries, since the atrioventricular concordance is present implicitly. In the group of cardiopathies with arterioventricular concordance and atrioventricular discordance the designation could be, for example, atrioventricular discordances with transposition of the great arteries, a malformation commonly known as corrected transposition of the great arteries (Van Praagh, 1972).

TABLE

\begin{tabular}{|c|c|c|c|}
\hline $\begin{array}{l}\text { Relation } \\
\text { between } \\
\text { the great } \\
\text { arteries } \\
\text { with the } \\
\text { ventricles } \\
\text { and the } \\
\text { atria }\end{array}$ & $\begin{array}{l}\text { I: Arterioventricular } \\
\text { concordance } \\
\text { II: Arterioventricular } \\
\text { discordance }\end{array}$ & $\begin{array}{l}\text { With atrioventricular } \\
\text { concordance } \\
\text { With atrioventricular } \\
\text { discordance } \\
\text { With atrioventricular } \\
\text { concordance } \\
\text { With atrioventricular } \\
\text { discordance }\end{array}$ & $\begin{array}{l}\text { In } \\
\text { situs } \\
\text { solitus } \\
\text { or in } \\
\text { situs } \\
\text { inversus }\end{array}$ \\
\hline
\end{tabular}

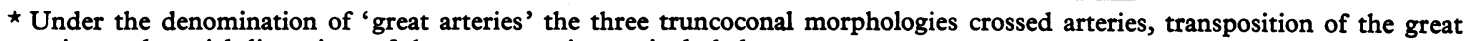
arteries, and partial distorsions of the great arteries are included.

FIG. 4 Specimen No. 3334. Anatomical specimen of a case of arterioventricular discordance with atrioventricular discordance in situs solitus and crossed arteries. A) Internal view of the anatomically right atrium $(R A)$ communicating with the anatomically left ventricle $(L V)$ both located on the right side. B) Internal view of the anatomically left atrium $(L A)$ communicating with the anatomically right ventricle $(R V)$ both located on the left side. C) Internal view of the anatomically right ventricle $(R V)$ located on the left side, from which the pulmonary artery arises $(P A)$ in front of the horizontal portion of the crista supraventricularis $(C S)$. D) External view of the heart and the great arteries. Note that the pulmonary artery $(P A)$ crosses the aorta ventrally and is directed from right to left despite the fact that the anatomically right ventricle is located on the left side. 

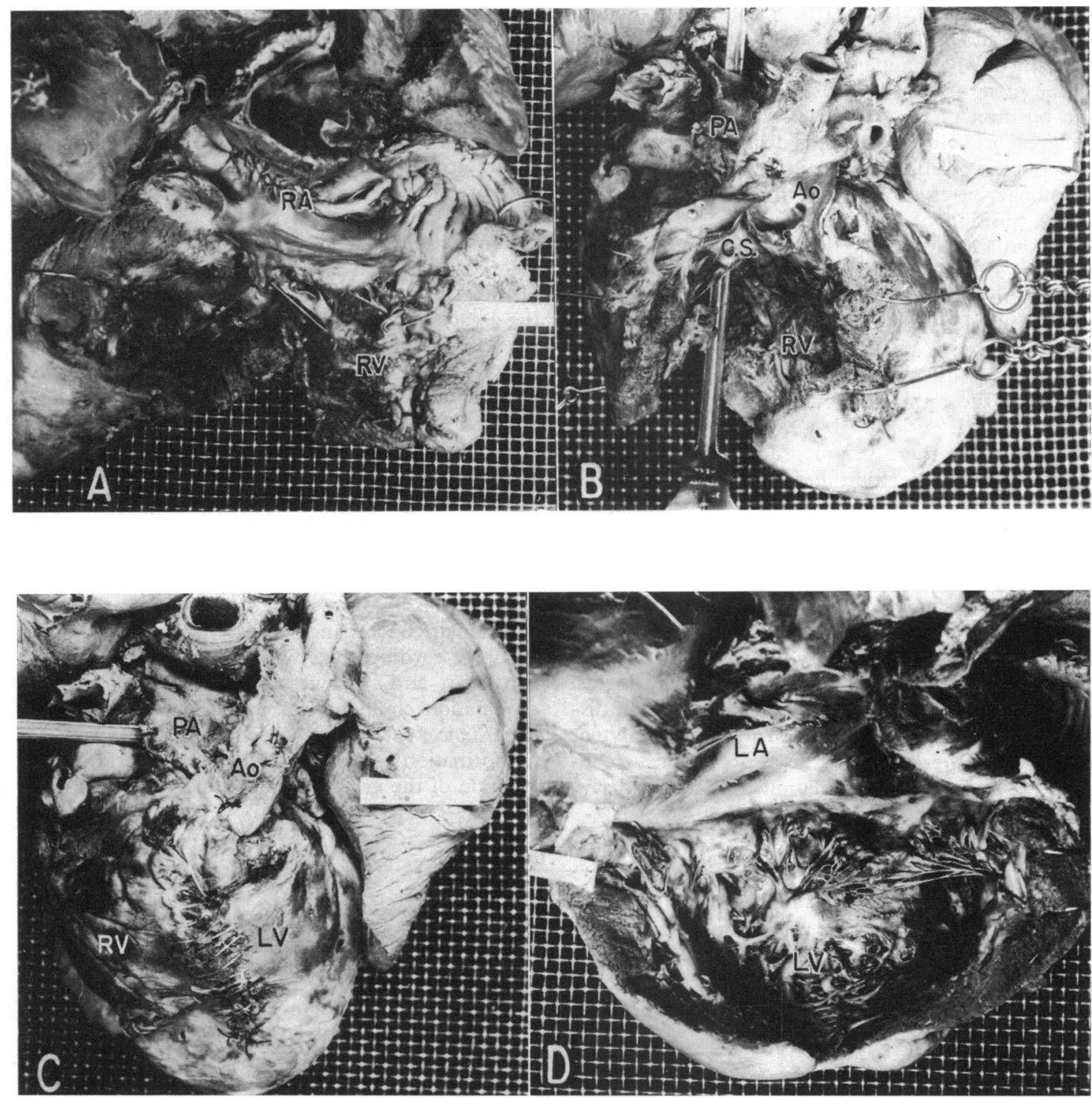

FIG. 5 Specimen No. 3965. Anatomical specimen of a case of arterioventricular discordance with atrioventricular concordance in situs solitus with transposition of the great arteries. A) Internal view of the anatomically right atrium $(R A)$ communicating with the anatomically right ventricle $(R V)$ both located on the right side. B) Internal view of the anatomically right ventricle $(R V)$ located on the right, from which the aorta arises $(A o)$ in front of the horizontal portion of the crista supraventricularis (CS). Note the stylus placed in the pulmonary artery $(P A)$ which arises from this ventricle. The aorta $(A o)$ is located on the left of the pulmonary artery $(P A) . \mathrm{C})$ External view of the heart. Note the aorta $(A o)$ anterior, parallel and located on the left side of the pulmonary artery $(P A)$, despite the fact that the anatomically right ventricle $(R V)$ is located on the right; anatomically left ventricle $(L V)$ located on the left side. D) Internal view of the anatomically left atrium $(L A)$ communicating with the anatomically left ventricle $(L V)$ both located on the left side. 

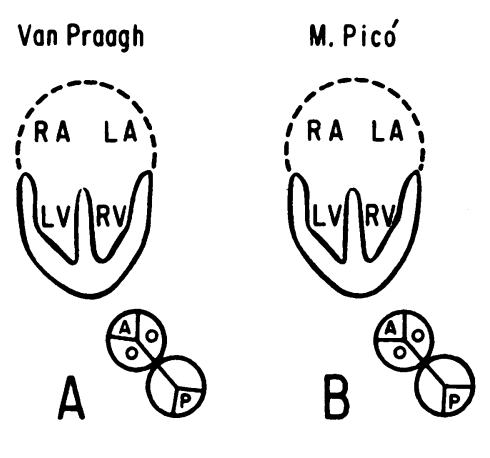

3334

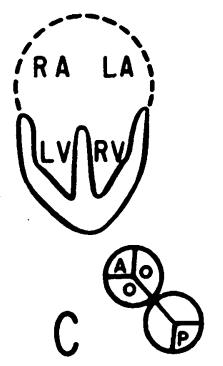

Pérez Treviño

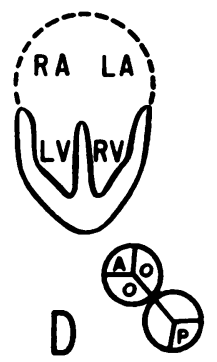

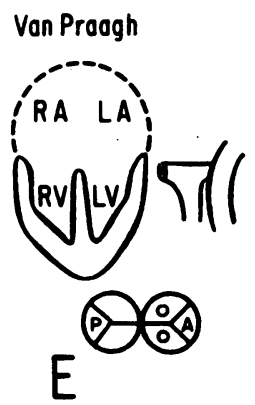
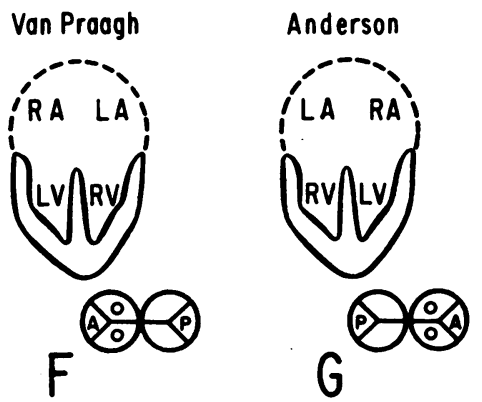

3965
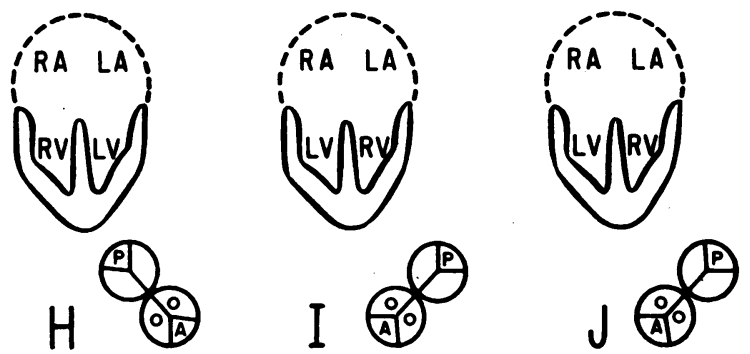

FIG. 6 Diagram representing the anatomical specimens of our collection and those of the literature exhibiting arterioventricular discordance and atrioventricular concordance or discordances. For references, see text.

Key to abbreviations: $R A=$ Right atrium. $L A=$ Left atrium. $R V=$ Right ventricle. $L V=$ Left ventricle. $A=$ Aortic sigmoid valve cusps. $P=$ Pulmonary sigmoid valve cusps.

\section{Illustrative cases}

\section{I) Anatomical description of our cases}

Specimen No. 3334 (Fig. 4) This is an example of situs solitus. The atrium placed on the right has the anatomical features of a right atrium (crista terminalis, sinus portion and pectineal muscles (Fig. 4A)) and receives both the superior and inferior venae cavae. It exhibits an atrial septal defect of the fossa ovalis type and it communicates by way of an atrioventricular orifice, which in turn exhibits three valvular leaflets, with a ventricle placed on the right side which has the anatomical features of a left ventricle: two groups of papillary muscles, smooth septal surface in its upper twothirds and trabeculated in its lower third (Fig. 4A). There is hypertrophy and dilatation of this chamber and a ventricular septal defect in the membranous portion with the aorta straddling the septum equally over each ventricle. The infundibulum of this ventricle is directed from right to left and from the back foward, while the 
aorta arising from it is oriented from the back forward and from left to right, that is, opposite to the spatial orientation of the infundibulum. The aortic valvular plane with respect to the pulmonary valvular plane corresponds to the orientation of the aorta and not that of its infundibulum.

The four pulmonary veins connect to a common sinus which enters the atrium placed on the left side which exhibits smooth walls, a feature characteristic of an anatomically left atrium (Fig. 4B). This chamber communicates by way of an atrioventricular orifice, guarded by three leaflets, with the ventricle bearing the anatomical features of a right ventricle: the anterior papillary muscle, the moderator band, the septal and horizontal portion of the crista supraventricularis, and a septal surface which is trabeculated all over (Fig. $4 \mathrm{~B}, \mathrm{C}$ ). The interventricular septal defect is seen behind the horizontal portion of the crista supraventricularis, and in front of this structure the pulmonary artery originates from an infundibulum directed from left to right and from the back forward, while the pulmonary artery which crosses the aorta ventrally is oriented from the front backward and from right to left, i.e. opposite to the spatial orientation of the infundibulum (compare $\mathrm{C}$ with $\mathrm{D}$ in Fig. 4). The pulmonary valvular plane, with respect to the aortic valvular plane corresponds with the orientation of the pulmonary artery and not with that of its infundibulum.

The orientation of the valvular planes and of the great arteries between themselves is that which ordinarily corresponds with crossed arteries when the anatomically right ventricle is placed on the right, whereas, in this case, the anatomically right ventricle is placed on the left (Fig. ${ }_{4 C}$ ).

Diagnosis: Situs solitus. Discordant crossed arteries. Atrioventricular discordance. Atrial and ventricular septal defects. Abnormal number of valvular leaflets. Persistence of the sinus of the pulmonary veins opening into the left atrium.

Specimen No. 3965 (Fig. 5) This is also an example of situs solitus. The atrium placed on the right side has the anatomical features of a right atrium (crista terminalis, sinus portion, and pectineal muscles (Fig. 5A)) and it receives the superior and the inferior venae cavae. It exhibits an atrial septal defect of the fossa ovalis type and it communicates by way of an atrioventricular orifice, guarded by three valvular leaflets, with a ventricle placed on the right side exhibiting the anatomical features of a right ventricle: horizontal and septal portions of the crista supraventricularis, anterior papillary muscle, moderator band, and a characteristic trabeculated septal surface (Fig. 5A, B). The aorta arises in front of the horizontal portion of the crista supraventricularis, and it is anterior, parallel to, and placed on the left side of the pulmonary artery (Fig. 5B, C). The pulmonary artery originates from this ventricle exclusively, behind the crista supraventricularis (Fig. 5B); its valvular orifice is placed on the right side with respect to the aortic orifice and with a bulbar muscle which separates it from the tricuspid orifice. There is hypertrophy of the walls of this chamber. There is a large ventricular septal defect of the midposterior type which extends from the posterior aspect of the crista supraventricularis to the posterior wall of the heart.

The four pulmonary veins drain separately into the atrium placed on the left side. It exhibits smooth walls, i.e. features pertaining to the anatomically left atrium (Fig. 5D). This chamber is dilated and it communicates by way of an atrioventricular orifice, guarded by two valve leaflets, with a ventricle bearing the features of an anatomically left ventricle: two groups of papillary muscles, smooth septal surface in the upper two-thirds and trabeculated in the lower third (Fig. 5D). This chamber is dilated and its walls are hypertrophied; no vessel originates from it. The orientation of the valvular planes, as well as the relation of the aorta with respect to the pulmonary artery, is that seen in transposition of the great arteries when there is a double outflow tract of an anatomically right ventricle placed on the left side, whereas, in this case, the anatomically right ventricle is placed on the right (Fig. 5B, C).

Diagnosis: Situs solitus. Discordant transposition of the great arteries. Double outlet of the anatomically right ventricle. Atrial and ventricular septal defects.

\section{Discussion}

Our cases and the material previously reported in connexion with discordance of the great arteries with the position of the ventricles will be grouped according to the three truncoconal morphologies, i.e. crossed arteries, partial distorsion of the great arteries, and transposition of the great arteries, in order to facilitate discussion.

In the group of crossed arteries, we have found four specimens with discordance of the great arteries with the position of the ventricles (discordant great arteries). The cases are those of Van Praagh and Van Praagh (1966), Martínez-Picó and Muñoz (1967), Pérez Treviño et al. (1972), and our own specimen No. 3334, described above. All have the aorta and the pulmonary artery crossing each other in space and the pulmonary artery directed from right to left as ordinarily seen when the anatomically right ventricle is on the right. Also, the relation of their valvular planes corresponds to that of an anatomically right ventricle placed on the right (compare Fig. 6A, B, C, and D with $2 A$ ). It is important, however, to point out that in these instances, the anatomically right ventricle is placed on the left (Fig. 4C and 6A, B, C, D). Therefore, the relation between the great arteries and their valvular planes with the position of the ventricles is that which is seen in arterioventricular discordances when the anatomically right ventricle is on the left side (compare Fig. 6A, B, C, D with 2J) (discordant crossed arteries). Also, the four specimens have the anatomically right atrium placed on the right side 
and it communicates with the anatomically left ventricle placed on the same side (atrioventricular discordance) (Fig. 6A, B, C, and D). This latter feature makes us include these specimens in the subgroup of discordant crossed arteries with atrioventricular discordance (Fig. 2J) which is an anatomical condition caused, from the embryological standpoint, by a disturbance affecting exclusively the bulboventricular loop (Fig. ID). On the other hand, the case published by Espino-Vela et al. (1970) corresponds to the group of atrioventricular discordances (anatomically right atrium with anatomically left ventricle) with crossed arteries in situs inversus (anatomically right atrium on the left side) but with concordance of the great arteries with the position of the ventricles (Fig. 3D), since the direction of the pulmonary artery and the relation of the valvular planes are those observed when the anatomically right ventricle is on the right side as in this case (compare Fig. 2A with $3 \mathrm{D}$ ). Therefore, the case of Espino-Vela et al. (1970) owes its origin to an embryological disturbance affecting simultaneously the truncus and the bulboventricular loop in situs inversus which determines the atrioventricular discordance and the concordance of the great arteries and their valvular planes with the position of the ventricles, so that this malformation was not caused by an isolated inversion of the bulboventricular loop (Van Praagh, 1972). There is another case, previously published by us (De la Cruz and Nadal-Ginard, 1972), of atrioventricular discordance in situs solitus with crossed arteries and with arterioventricular concordance also (Fig. 2D). Therefore, the direction of the pulmonary artery and the relation of its valvular planes are those seen when the anatomically right ventricle is on the left side, as was the case in the specimen (compare Fig. 2D with 3A). It was thus caused by an embryological disturbance affecting the loop and the truncus simultaneously as the case of Espino-Vela et al. (1970) but occurring in situs solitus (Fig. $\mathrm{rB}, \mathrm{b}_{1}, \mathrm{~b}_{2}, \mathrm{~b}_{5}, \mathrm{~b}_{6}$ ). In fact, the only cases so far described, which illustrate isolated ventricular inversion (Van Praagh and Van Praagh, 1966) with crossed arteries, are these four (Fig. 2J, and 6A, B, C, and D) in which the embryological disturbance took place exclusively in the bulboventricular loop without affecting the truncus (Fig. ID).

In the group of partial distorsion of the great arteries, we have found 3 specimens described, which belong to discordance of the great arteries with the position of the ventricles (discordant partial distorsions of the great arteries). Two of the specimens (Van Praagh, 1972; Anderson et al., 1972) have the aorta and the aortic plane to the left of the pulmonary artery and its sigmoid valve cusps (Fig. 6E and $G$ ), a relation observed when the anatomically right ventricle is placed on the left side in partial distorsion of the great arteries (Fig. $2 \mathrm{~F}$ and $3 \mathrm{C}$ ). It is important to point out, however, that these cases had an anatomically right ventricle placed on the right side (compare Fig. $6 \mathrm{E}$ with $2 \mathrm{~F}$ and $6 \mathrm{G}$ with $\left.{ }_{3} \mathrm{C}\right)$. Therefore, the relation of the great arteries and their valvular planes with the position of the ventricles is that seen in discordance of the great arteries with the ventricles when the anatomically left ventricle is placed on the left (compare Fig. $6 \mathrm{E}$ with 2I and Fig. 6G with $3 \mathrm{~L}$ ). The other case of Van Praagh and Van Praagh (1967) shows the aorta and aortic valvular plane on the right side of the pulmonary artery and its sigmoid valve cusps (Fig. $6 \mathrm{~F}$ ), a relation seen when the anatomically right ventricle is placed on the right side in partial distorsion of the great arteries (Fig. $2 \mathrm{C}$ and $3 \mathrm{~F}$ ). It is important to point out, however, that this case had the anatomically right ventricle placed on the left side (compare Fig. 6F with $2 \mathrm{C}$ ), for which reason the relation of the great arteries and their valvular planes with the position of the ventricles is that which is seen in discordance of the great arteries with the position of the ventricles when the anatomically left ventricle is placed on the right side (compare Fig. 6F with 2L).

Examining the atrioventricular relations of these 3 cases of discordant partial distorsion of the great arteries, we find that one of the cases (Van Praagh 1972), which has the anatomically right ventricle placed on the right also, had the anatomically right atrium on the same side (the atria in the position of situs solitus), showing, therefore, atrioventricular concordance (Fig. 6E). Consequently this case belongs to the subgroup of discordant partial distorsion of the great arteries with atrioventricular concordance, caused by a disturbance affecting the truncus exclusively and in which anatomically the relation of the great arteries and their valvular planes does not correspond to the position of the ventricles, while the atrioventricular relations are normal because the bulboventricular loop is not involved and it develops normally (Fig. IC, $c_{1}, c_{4}, c_{5}, c_{6}$ ). The other case of Van Praagh and Van Praagh (1967) had the anatomically left ventricle placed on the right side but the atrium located on the same side is the anatomically right atrium (atria in the position of situs solitus). This caused the anatomically right atrium to communicate with an anatomically left ventricle (atrioventricular discordance) (Fig. 6F). Therefore, this case belongs in the subgroup of discordant partial distorsions of the great arteries with atrioventricular discordance, which originate because of a disturbance affecting exclusively the bulboventricular loop, which simultaneously determines the atrioventricular discordance and that of the great arteries 
and their valvular planes with the position of the ventricles (Fig. ID, $d_{1}, d_{4}, d_{5}, d_{6}$ ). The case of Anderson et al. (1972), referred to, had the anatomically right ventricle on the right side and the anatomically left atrium on the right side, which is the normal position of the atria in situs inversus. Therefore, the anatomically left atrium communicated with the anatomically right ventricle both placed on the same side, i.e. atrioventricular discordance (Fig. 6 G). Thus this case belongs to the subgroup of discordant partial distorsion of the great arteries with atrioventricular discordance in situs inversus (compare Fig. 6G with $3 \mathrm{~L}$ ). This malformation originates because of a disturbance affecting exclusively the bulboventricular loop, which in this case developed with a right-sided convexity and a left-sided concavity which is abnormal for situs inversus. It causes, simultaneously, the atrioventricular discordance and that of the great arteries and their valvular plane with the position of the ventricles. This case of Anderson et al. (1972) in situs inversus is the mirror-image of the case of Van Praagh and Van Praagh (1967), which exhibits discordant partial distortions of the great arteries with atrioventricular discordance (compare Fig. 6G with 6F), since both originated because of a disturbance affecting exclusively the bulboventricular loop but in different situs.

In the group of transpositions of the great arteries we have found 2 cases reported (Lev and Rowlatt, I96I) and our own specimen No. 3965, which belong in the group of discordant transposition of the great arteries. In our case, the transposed aorta and aortic valvular plane are placed to the left of the pulmonary artery and its sigmoid valve cusps (Fig. 5C and $6 \mathrm{H}$ ), a relation observed when the anatomically right ventricle is placed on the left in transposition of the great arteries (compare Fig. $2 \mathrm{E}$ with $6 \mathrm{H}$ ), but it is important to point out that this case has the anatomically right ventricle placed on the right (Fig. 5B and 6H). Therefore, the relation of the pedicle of the great arteries and their valvular planes with the position of the ventricles is that which is present in discordant transposition of the great arteries when the anatomically left ventricle is placed on the left (compare Fig. $6 \mathrm{H}$ with $2 \mathrm{H}$ ). The atrioventricular relations in this case were concordant, since the anatomically right atrium placed on the right side communicated with the anatomically right ventricle placed on the same side (Fig. 5A and $6 \mathrm{H})$. This malformation is due to an embryological disturbance which affected only the truncus, for which reason there is a discordance of the great arteries and their valvular planes with the position of the ventricles, while the atrioventricular relations remain normal (atrioventricular concordance in situs solitus) (Fig. IC, $\mathrm{c}_{1}, \mathrm{c}_{3}, \mathrm{c}_{5}, \mathrm{c}_{6}$ ).
The two cases described by Lev and Rowlatt (I96I) also belong to the group of discordant transposition of the great arteries but with atrioventricular discordance in situs solitus (compare Fig. 6I and $\mathrm{J}$ with $2 \mathrm{~K}$ ). This malformation is due to an isolated inversion of the bulboventricular loop (Fig. I D) which causes simultaneously the atrioventricular discordance and the discordance of the great arteries and their valvular planes with the position of the ventricles (Fig. $I D, d_{1}, d_{3}, d_{5}, d_{6}$ ).

The so-called corrected transposition of the great arteries (De la Cruz et al., 1959) or ventricular inversion with transposition of the great arteries (De la Cruz et al., 1967) is characterized by atrioventricular discordance and concordance of the great arteries and their valvular planes with the position of the ventricles (Fig. IB, $b_{3}, b_{5}, b_{6}$ and $2 E$ and 3 $\mathrm{E})$; it originates from an embryological disturbance affecting the truncus and the bulboventricular loop simultaneously (De la Cruz et al., 1967) (Fig. I $\left.B, b_{1}, b_{3}, b_{5}, b_{6}\right)$, in contrast, the main feature in discordant transpositions of the great arteries is the presence of the discordance of the great arteries with the position of the ventricles, which may or may not be associated with atrioventricular discordance (Fig. $2 \mathrm{H}, \mathrm{K}$ and $3 \mathrm{H}, \mathrm{K}$ ). It follows that the discordant transpositions of the great arteries are caused by disturbances which affect only the truncus or the loop (Fig. IC and D).

\section{References}

Anderson, R. H., Arnold, R., and Jones, R. S. (1972). Dbulboventricular loop with L-transposition in situs inversus. Circulation, 46, 173.

Castro-Quezada, A., Nadal-Ginard, B., and de la Cruz, M. V. (1972). Experimental study of the formation of the bulboventricular loop in the chick. Fournal of Embryology and Experimental Morphology, 27, 623.

De la Cruz, M. V., Anselmi, G., Cisneros, F., Reinhold, M., Portillo, B., and Espino-Vela, J. (1959). An embryological explanation for the corrected transposition of the great vessels: additional description of the main anatomic features of this malformation and its varieties. American Heart fournal, 57, 104.

De la Cruz, M. V., and da Rocha, J. P. (1956). An ontogenetic theory for the explanation of congenital malformations involving the truncus and conus. American Heart fournal, 5x, 782.

De la Cruz, M. V., Espino-Vela, J., Attie, F., and MuñozCastellanos, L. (1967). An embryologic theory for ventricular inversions and their classification. American Heart Fournal, 73, 777.

De la Cruz, M. V., and Nadal-Ginard, B. (1972). Rules for the diagnosis of visceral situs, truncoconal morphologies, and ventricular inversions. American Heart fournal, 84, 19.

Espino-Vela, J., de la Cruz, M. V., Muñoz-Castellanos, L., Plaza, L., and Attie, F. (1970). Ventricular inversion without transposition of the great vessels in situs inversus. British Heart fournal, 32, 292. 
Lev, M., and Rowlatt, U. F. (196I). The pathologic anatomy of mixed levocardia. A review of thirteen cases of atrial or ventricular inversion with or without corrected transposition. American fournal of Cardiology, 8, 216.

Martinez-Picó, A., and Muñoz, A. (1967). Inversión ventricular. Transposición fisiológica de la circulación y relación aortopulmonar normal. Boletín de la Asociación Médica de Puerto Rico, 59, 26.

Nadal-Ginard, B., and Garcia, M. P. (1972). The morphologic expression of each cardiac primordium in the chick embryo. Fournal of Embryology and Experimental Morphology, 28, 14r.

Pérez-Treviño, C., Hurtado del Río, D., and Holden, A. M. (1972). Inversión ventricular aislada. Archivos del Instituto de Cardiología de México, 42, 966.

Rosenquist, G. C., and DeHaan, R. L. (1966). Migration of precardiac cells in the chick embryo: a radioautographic study. Contributions to Embryology, Carnegie Institution, 38, II I (No. 263).

Stalsberg, H., and DeHaan, R. L. (1969). The precardiac areas and formation of the tubular heart in the chick embryo. Developmental Biology, 19, 128.
Van Mierop, L. H. S. (1969). Embryology. In CIBA Collection of Medical Illustrations, vol. 5, p. III. Ed. by F. H. Netter. Ciba Pharmaceutical Co., Summit, N. J.

Van Praagh, R. (1972). Segmental approach to diagnosis in congenital heart disease. In Birth Defects, p. 4. Williams and Wilkins Company, Baltimore.

Van Praagh, R., and Van Praagh, S. (1966). Isolated ventricular inversion. A consideration of the morphogenesis, definition and diagnosis of nontransposed and transposed great arteries. American fournal of Cardiology, 17, 395.

Van Praagh R., and Van Praagh, S. (1967). Anatomically corrected transposition of the great arteries. British Heart fournal, 29, 112.

Van Praagh, R., Van Praagh, S., Vlad, P., and Keith, J. D. (1964). Anatomic types of congenital dextrocardia. Diagnostic and embryologic implications. American fournal of Cardiology, 13, 510.

Requests for reprints to Dr. María V de la Cruz, Instituto Nacional de Cardiología, Av. Cuahtémoc No. 300, México 7, D.F. 